\title{
Stagnation point flow, heat and mass transfer over a nonlinear stretching sheet withSuction/Injection
}

\author{
Ch. Achi Reddy and Prof. B. Shankar
}

\begin{abstract}
The present paper is to investigate the combined effects of the heat and mass transfer on the unsteady twodimensional boundary layer flow over a nonlinear stretching sheet in the presence of Stagnation point and Suction/ Injection.The governing nonlinear partial differential equations have been reduced to the coupled nonlinear ordinary differential equations by the similarity transformations. The resulting equations are solved numerically by using Keller box method. The velocity, temperature and concentration distributions are discussed numerically and presented through graphs.
\end{abstract}

Keywords- Boundary layer flow; nonlinearstretching sheet; Stagnation point; Suction/Injection, Magneto hydrodynamics; Casson fluid.

\section{INTRODUCTION}

Cassonnanofluid in cylindrical geometry has important in blood flow. Mathematicians as well as medical researchers are widely working on Cassonnanofluid model. Boundary layer flow of Casson fluid over different geometries is considered by many authors in recent years. Nadeem et al. [1] presented the MHD flow of Casson fluid over an exponentially shrinking sheet. The analytical solution arising differential system has been computed by the Adomain Decomposition Method. Fredrickson [2] studied the steady flow of a Casson fluid in a tube. Magyari and Keller [3] provided both analytical and numerical solutions for boundary layer flow over an exponentially stretching surface with an exponential temperature distribution. Hayat et al. [4] investigated the Soret and Dufour effects on the MHD flow of the Casson fluid over a stretchedsurface. The relevant equations are first derived, and the series solutions are constructed by the homotopic procedure. Shehzad et al [5] analysed the effect of mass transfer in the magnetohydrodyanamic flow of a Casson fluid over a porous stretching sheet in the presence of a chemical reaction and suction. It is observed that the Cassion parameter and Hartman number have similar effects on the velocity in a qualitative sense. It is further analysed that the concentration decreases rapidly in comparison to the fluid velocity when the values of the suction parameter are increased.

Ch. Achi Reddy

MLR Institute of Technology, Hyderabad India
Many processes in engineering occur at high temperatures and the full understanding of the effect of radiation on the rate of heat transfer is necessary in the design of equipment. The effect of radiation on the boundary layer flow was studied by Elbashbeshy and Dimian [6], Hossain et al.[7], Bataller [8] and Cortell [9 ]. The radiation effect is considered by Bataller [8] in the study of boundary layer flow over a static flat plate (Blasius flow) andCortell [10]

In the present study, heat and mass transfer in MHD Nano fluid over a nonlinear stretching sheet in presence of suction/injection have been investigated. The governing partial differential equations of the flow are converted into nonlinear coupled ordinary differential equation by the technique of similarity transformation and then solved numerically. The effect of parameters on velocity, temperature and concentration profiles are discussed and presented through graphs.

\section{MATHEMATICAL FORMULATION}

Consider a steady two-dimensional MHD flow of viscous, incompressible, electrically-conducting and radiating fluid over a vertical stretching surface in the presence of heat source/sink and mass transfer. The $\mathrm{x}$-axis is coincident with the vertical surface and the $y$-axis is perpendicular to the surface. $\mathrm{U}$ and $\mathrm{v}$ are defined as the velocity components along the $\mathrm{x}$-and $\mathrm{y}$-axes, respectively. The stretching sheet velocity is assumed to be in the form of $u=a x^{m}$ where $a$ is positive constant. The velocity at short distance from the surface allows a thin boundary layer to develop near the surface. The surface temperature, ${ }^{T}$ is assumed to follow the power law $T_{w}=T_{\infty}+b x^{n}$ where $b$ is a constant and $T_{\infty}$ is the ambient temperature. The surface concentration, $C_{w}$ is assumed to follow the power law $C_{w}=C_{\infty}+c x^{n}$ where $C_{\infty}$ is the ambient concentration. It is also assumed that the magnetic Reynolds number is small in such a way that the induced magnetic field is negligible. Both viscous dissipation and Ohmic heating terms are neglected because their values are generally small. Under these assumptions along with Boussinesq and boundary layer approximations, the governing equations of partial differential equations for the conservation of mass, momentum, energy and species are 


$$
\begin{gathered}
\frac{\partial u}{\partial x}+\frac{\partial v}{\partial y}=0 \\
u \frac{\partial u}{\partial x}+v \frac{\partial u}{\partial y}=v\left(B+\frac{1}{B}\right) \frac{\partial^{2} u}{\partial y^{2}}+g \beta_{T}\left(T-T_{\infty}\right)+ \\
g \beta_{C}\left(C-C_{\infty}\right)-\frac{\sigma B(x)}{\rho}\left(u_{\infty}-u\right) \\
u \frac{\partial T}{\partial x}+v \frac{\partial T}{\partial y}=\alpha \frac{\partial^{2} T}{\partial y^{2}}-\frac{1}{\rho c} \frac{\partial q_{r}}{\partial y}+\frac{D_{B} k_{T}}{c_{s} c_{p}} \frac{\partial^{2} C}{\partial y^{2}}+ \\
\frac{q_{0}}{\rho c_{p}}\left(T-T_{\infty}\right) \\
u \frac{\partial C}{\partial x}+v \frac{\partial C}{\partial y}=D_{B} \frac{\partial^{2} C}{\partial y^{2}}+\frac{D_{B} k_{T}}{T_{B}} \frac{\partial^{2} T}{\partial y^{2}}
\end{gathered}
$$

The boundary conditions for the velocity, temperature and concentration fields are

$$
\begin{aligned}
& u=a x^{m}, v=-v_{w}(x), T=T_{w}(x), C=C_{w}(x) \text { at } y=0 \\
& u \rightarrow 0, T \rightarrow T_{\infty}, C \rightarrow \infty \text { as } y \rightarrow \infty
\end{aligned}
$$

where $T$ and $C$ is the fluid temperature and temperature in the boundary layer, $B(x)$ is the variable magnetic field strength, ${ }^{\nu}$ is the kinematic viscosity, $\rho$ is the density of the base fluid, $\sigma$ is the electric conductivity, $k$ is the thermal conductivity, $\alpha=\frac{k}{\rho c_{p}}$ is the thermal diffusivity, $\beta$ is the coefficient of thermal expansion, $q_{0}$ is the heat generation or absorption coefficient such that $q_{0}>0$ corresponds to heat generation while $q_{0<0}$ corresponds to heat absorption, ${ }^{g}$ is the acceleration due to gravity, ${ }^{c} c_{p}$ is the specific heat at constant pressure, $q_{r}$ is the radioactive heat flux, $k_{T}$ is the thermal diffusion ratio, $c_{s}$ is the concentration susceptibility, $T_{B}$ is the mean fluid temperature and $D_{B}$ is the mass diffusivity.

By using the Rosseland approximation is defined as [28], the radiative heat flux $q_{r}$ is given by

$$
q_{r}=-\frac{4 \sigma^{*}}{3 k^{*}} \frac{\partial T^{4}}{\partial y}
$$

Where $\sigma^{*}$ is the Stefan-Boltzmann constant and $k^{*}$ is the mean absorption coefficient. It is assumed that the temperature differences between the free stream $T_{\infty}$ and the local temperature ${ }^{T}$ is small enough expanding $T^{4}$ in a Taylor series about $T_{\infty}$ and neglecting higher order terms results;

$$
T^{4} \cong 4 T_{\infty}^{3} T-3 T_{\infty}^{4}
$$

After substituting Eqs. (6) and (7) in Eq.(3), it will be reduces to

$$
\begin{aligned}
& u \frac{\partial T}{\partial x}+v \frac{\partial T}{\partial y}=\left[\alpha+\frac{16 \sigma^{*} T_{\infty}^{3}}{3 \kappa^{*}(\rho c)_{f}}\right] \frac{\partial^{2} T}{\partial y^{2}}+ \\
& \frac{D_{B} k_{T}}{c_{s} c_{p}} \frac{\partial^{2} C}{\partial y^{2}}+\frac{q_{0}}{\rho c_{p}}\left(T-T_{\infty}\right)
\end{aligned}
$$

The continuity Equ (1) is satisfied by the Cauchys Riemann equation

$$
u=\frac{\partial \psi}{\partial y}, \quad v=-\frac{\partial \psi}{\partial x}
$$

Where $\psi=\psi(x, y)$ is the stream function. When the variable magnetic field $B(x)=B_{0} x^{(m-1) / 2}$.

The momentum, energy and spices equations along with the boundary conditions can be transformed into a system of coupled ordinary differential equations by the following transformation:

$$
\begin{aligned}
& \psi=\left(a v x^{m-1}\right)^{\frac{1}{2}} f(\eta), \eta=\left(\frac{a x^{m-1}}{v}\right)^{\frac{1}{2}} y, \\
& \theta(\eta)=\frac{T-T_{\infty}}{T_{w}-T_{\infty}}, \phi(\eta)=\frac{C-C_{\infty}}{C_{w}-C_{\infty}}
\end{aligned}
$$

Where $f(\eta)$ is the dimensionless stream function, $\theta(\eta)$ is the dimensionless temperature, $\phi(\eta)$ is the dimensionless concentration, $\eta_{\text {is }}$ the similarity variable.

As such Equs.(9 - 10), Eqs. (2), (4) and (8) reduce to the following system of nonlinear ordinary differential equations.

$$
\begin{aligned}
& \left(B+\frac{1}{B}\right) f^{\prime \prime \prime}+\frac{m+1}{2} f f^{\prime \prime}-m f^{\prime 2}+m \varepsilon^{2}+ \\
& \lambda \theta+\delta \phi+M^{2}\left(\varepsilon-f^{\prime}\right)=0 \\
& \frac{1}{\operatorname{Pr}}(1+R) \theta^{\prime \prime}+\frac{m+1}{2} f \theta^{\prime}-n f^{\prime} \theta+D f \phi^{\prime \prime}+Q \theta=0 \\
& \frac{1}{L e} \phi^{\prime \prime}+\frac{m+1}{2} f \phi^{\prime}-n f^{\prime} \phi+S r \theta^{\prime \prime}=0
\end{aligned}
$$




$$
\begin{aligned}
& f=S, f^{\prime}=1, \theta=1, \phi=1 \text { at } \eta=0 \\
& f^{\prime}=\theta=\phi=0 \text { as } \eta \rightarrow \infty
\end{aligned}
$$

where

$$
\begin{aligned}
& M=\frac{\sigma B_{0}^{2}}{\rho a}, \lambda=\frac{G_{r x}}{\operatorname{Re}_{x}^{2}}, G_{r x}=\frac{g \beta a\left(T_{w}-T_{\infty}\right)}{v^{2} x^{3}}, \\
& \lambda=\frac{G_{c x}}{\operatorname{Re}_{x}^{2}}, G_{c x}=\frac{g \beta^{*} a\left(C_{w}-C_{\infty}\right)}{v^{2} x^{3}}, \operatorname{Pr}=\frac{v}{\alpha}, \varepsilon=\frac{b}{a} \\
& D f=\frac{D_{B} k_{T}\left(C_{W}-C_{\infty}\right)}{c_{s} c_{p}\left(T_{w}-T_{\infty}\right)}, \operatorname{Sr}=\frac{D_{B} k_{T}\left(T_{W}-T_{\infty}\right)}{c_{s} T_{B}\left(C_{w}-C_{\infty}\right)} \\
& Q=\frac{q_{0} v}{\rho c_{p} a x^{m-1}}, L e=\frac{v}{D_{B}}
\end{aligned}
$$

$M$ - the magnetic parameter, $\lambda$ - the thermal buoyancy parameter, $\delta$ - the solutal buoyancy parameter, $G r_{x}$-the thermal Grashof number, $G c_{x_{-}}$the solutalGrashof number, $\operatorname{Pr}$ - the prandtl number, $L e$ - Lewis number, $R_{\text {- radiation }}$ parameter.

The quantities of physical interest for this problem are the skinfrictioncoefficient $C_{f}$, the local Nusselt number $N u_{x}$, and the local Sherwood number $S h_{x}$, which are respectively defined as

$$
\begin{aligned}
& C_{f}=\frac{\tau_{\omega}}{\frac{1}{2} p U_{\omega}^{2}}, N u_{x}=-\frac{x}{\left(T_{w}-T_{\infty}\right)} \frac{\partial T}{\partial y}, \\
& S h_{x}=-\frac{x}{\left(C_{w}-C_{\infty}\right)} \frac{\partial C}{\partial y} \cdot \text { at } y=0, \\
& y=0 \\
& \frac{1}{2} \sqrt{\operatorname{Re}_{x}} \cdot C_{f}=f^{\prime \prime}(0),-\theta^{\prime}(0)=\frac{N u_{x}}{\sqrt{\operatorname{Re}_{x}}}, \\
& \frac{S h_{x}}{\sqrt{\operatorname{Re}_{x}}}=-\phi^{\prime}(0) \\
& \text { (17) } \quad \operatorname{Re}_{x}=u_{\omega}(x) \cdot \frac{x}{v} \text { is the local Reynolds number. }
\end{aligned}
$$

\section{NUMERICAL PROCEDURE}

The set of coupled non-linear governing boundary layer equations (11) - (13) together with the boundary conditions (14) - (15) are solved numerically by using Keller box method. First of all, higher order non-linear differential equations (11) - (13) are converted into simultaneous linear differential equations of first order.Linearize the resulting algebraic equations by using Newton's method and write them in matrix form.Solve the system of Line(rirequations by the block tridiagonal elimination technique.

In this method the following initial guesses are chosen:

$$
\begin{aligned}
& f_{0}(\eta)=(1+s)-e^{-\eta} \quad, \quad \theta_{0}(\eta)=e^{-\eta} \\
& \phi_{0}(\eta)=e^{-\eta}
\end{aligned}
$$

\section{RESULT AND DISCUSSION}

The problem of boundary layer of a Casson fluid over a nonlinear stretching sheet subject to a transverse magnetic field in the presence of Suction/Injection is analysed. The governing non - linear ordinary differential equations are solved using Keller box method.

Table 1 Numerical values of $f^{\prime \prime}(0)$ and - $-\theta^{\prime}(0)$ at the sheet for different values of $M$ when $\operatorname{Pr}=\lambda=m=n=1$ and $\delta=R=D f=S r=L e=\varepsilon=S=0{ }_{, \mathrm{C}}$ omparison of the present results with that of B. Nagabusanam Reddy et al. [18]

\begin{tabular}{|l|l|l|l|l|}
\hline \multirow{4}{*}{$M$} & \multicolumn{2}{|c|}{$\begin{array}{c}\text { B. Nagabusanam } \\
\text { Reddy et al. [18] }\end{array}$} & \multicolumn{2}{|c|}{ Present results } \\
\cline { 2 - 5 } & $-f^{\prime \prime}(0)$ & $-\theta^{\prime}(0)$ & $-f^{\prime \prime}(0)$ & \multicolumn{1}{|c|}{$-\theta^{\prime}(0)$} \\
& & & & \\
\hline 0.0 & 0.560811 & 1.087250 & 0.560674 & 1.087250 \\
0.1 & 0.565906 & 1.087250 & 0.565771 & 1.0863327 \\
0.2 & 0.581081 & 1.086250 & 0.580954 & 1.083322 \\
0.5 & 0.683073 & 1.083240 & 0.682977 & 0.063052 \\
1 & 1.000000 & 1.063010 & 1.000000 & 1.000000 \\
2 & 1.901350 & 1.000060 & 1.896839 & 0.831090 \\
5 & 4.926900 & 0.758217 & 4.915603 & 0.470235 \\
& & & & \\
\hline
\end{tabular}

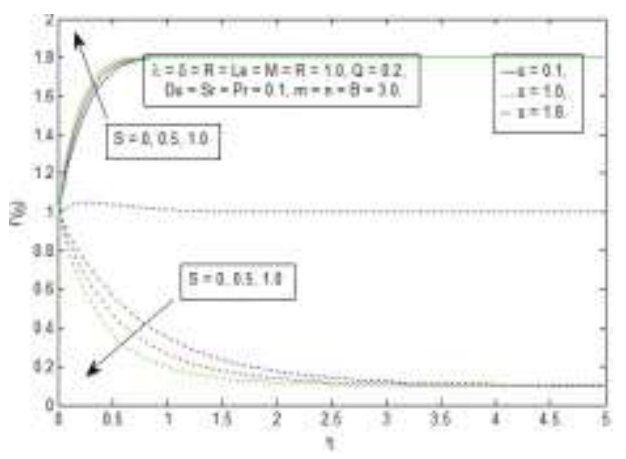

Figure 1: Velocity profile against $\eta_{\text {for different values of }} S$ 
Proc. of Fifth International Conference On Advances in Civil, Structural and Mechanical Engineering -ACSM 2016 Copyright (C) Institute of Research Engineers and Doctors, USA .All rights reserved.

ISBN: 978-1-63248-105-4 doi: 10.15224/ 978-1-63248-105-4-22

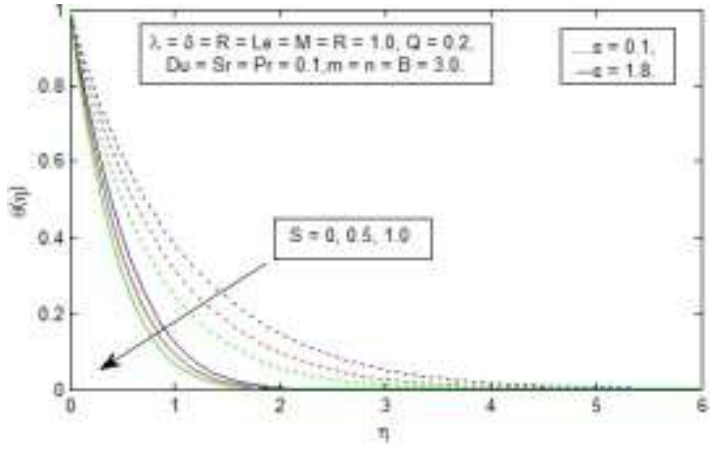

Figure 2: Temperature profile against $\eta_{\text {for different values of }} S$

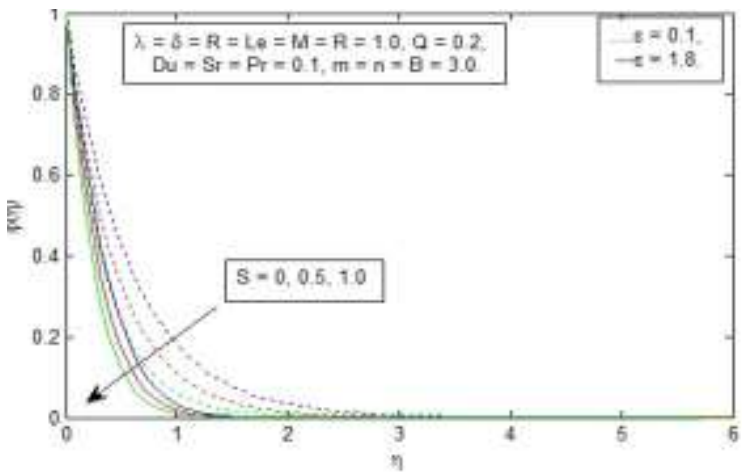

Figure 3: Concentration profile against $\eta_{\text {for different values of }} S$

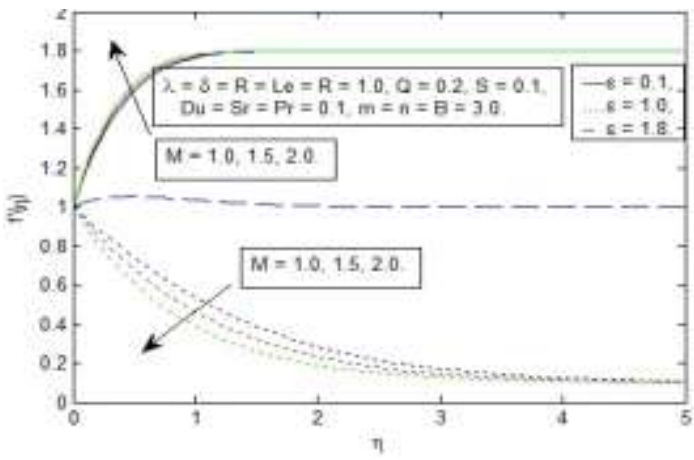

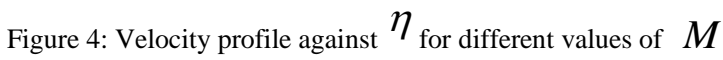

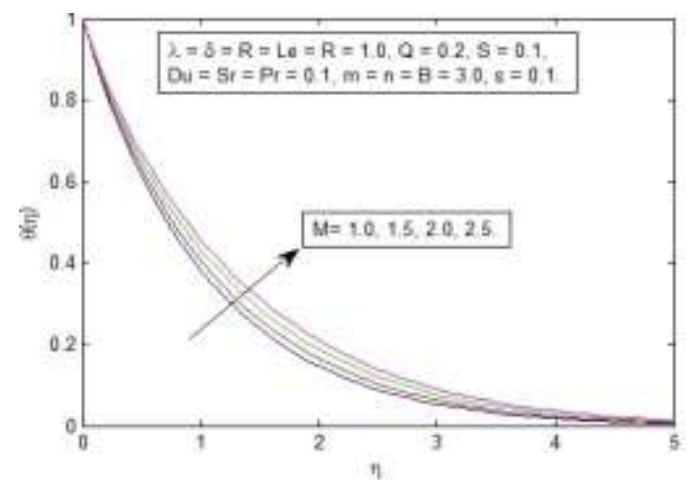

Figure 5: Temperature profile against $\eta_{\text {for different values of } M}$

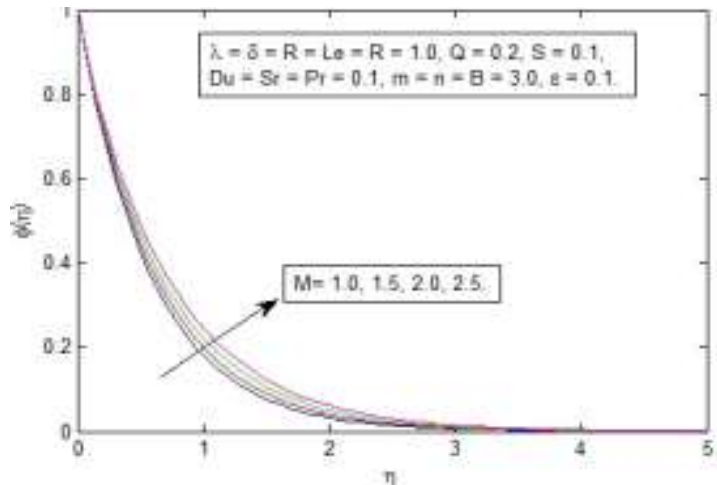

Figure 6: Temperature profile against $\eta_{\text {for different values of } M}$

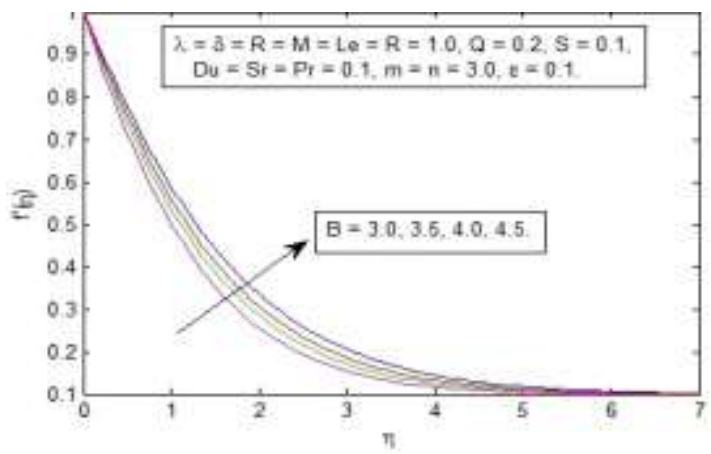

Figure 7: Velocity profile against $\eta_{\text {for different values of } B}$

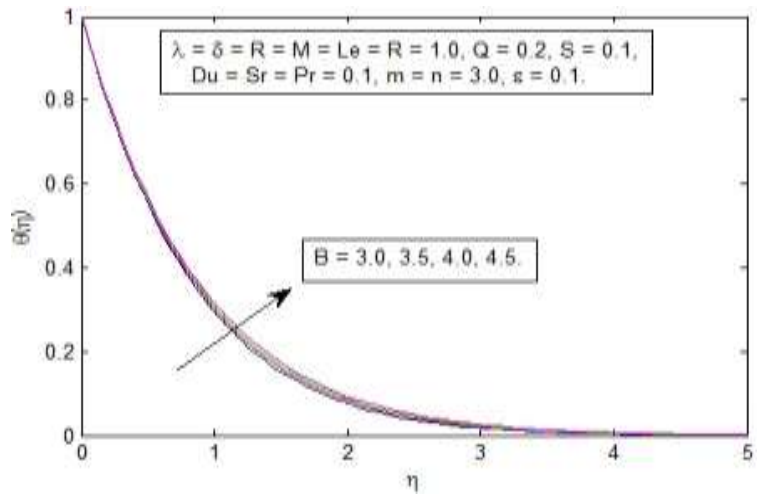

Figure 8: Temperature profile against $\eta_{\text {for different values of } B}$

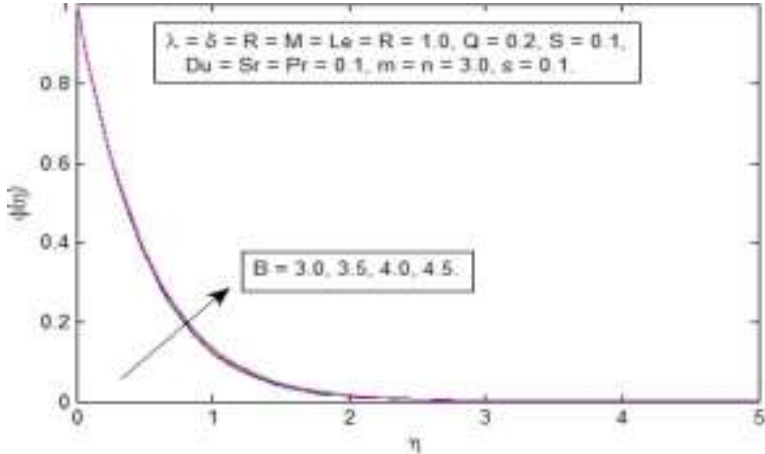

Figure 9: Concentration profile against $\eta_{\text {for different values of } B}$

Figures $1-3$ demonstrate the effects of suction parameter $S$ on velocity, temperature and nanoparticle volume fraction. When $\varepsilon>1 \& \varepsilon<1$ the fluid velocity decreases significantly with increasing values of suction parameter while it is found to enhance 
with blowing. The presence of suction would result in the reduction of the thickness of the boundary layer. The absence of suction represent the case of non-porous stretching sheet. In the case of blowing $(S<0)$ an opposite effect is observed. The effect of suction parameter on temperature and concentration is similar to that on the velocity.

Figures $4-6$ present the velocity, temperature and concentration for a variation of the magnetic parameter. It is observed that the presence of a magnetic field reduces the velocity when $\varepsilon>1 \& \varepsilon<1$. Higher value of Lorentz force further reduces the velocity and consequently the thickness of boundary layer reduces. However the impact of $M$ on temperature and concentration is less when compared to that on velocity.

Figures $7-9$ indicate the effect of the yield stress parameter/ Casson parameter. It is clear that the velocity decreases with $B$. It may be noted that increased value of $B$ imply a decrease in the yield stress of the Casson fluid and thus facilitates the flow of the fluid. It is observed that increasing values of the Casson parameter enhance the temperature as well as the nanoparticle volume fraction.

\section{CONCLUSIONS}

The present paper is analyses the influence of stagnation point and suction/ injection effects on MHD boundary layer flow, heat and mass transfer flow over a nonlinear stretching sheet. The resulting partial differential equations are nondimensionalised, simplified, and solved by implicit finite difference scheme, known as Keller box method. From the present numerical study the following conclusions can be drawn.

(1) The Casson fluid parameter, magnetic parameter and suction parameter produce a reduction in the velocity and the boundary layer thickness.

(2) The influence of Casson fluid parameter and magnetic parameter on temperature and nanoparticle volume fraction is to enhance temperature and concentration.

(3) Temperature and concentration profiles decreased due to increases inSuction parameter

\section{Reference:}

[1] Nadeem, S., Haq, RU., Lee, C. MHD flow of a Casson fluid over an exponentially shrinking sheet, ScientiaIranica., vol.19, pp.1550-1553, 2012.

[2] Fredrickson, A.G. Principles and Applications of Rheology, Prentice Hall, Englewood Cliffs, NJ, USA.

[3] Magyari, E., Keller, B Heat and mass transfer in the boundary layers on an exponentially stretching continuous surface, J. Phys. Appl. PHYS., vol.32, pp.577-585, 1999.

[4] Hayat, T., Shehzad, S. A., Alsaedi, A. Soret and Dufour effects on MHD flow of Cassion fluid, Applied Mathematics. Mech. - Engl.Ed. vol.33, pp.1301-1312, 2012

[5] Shehzad, S. A.,Hayat, T., Qasim, M. and Asghar, S., Effects of mass transfer on MHDflow of Casson fluid with chemical reactionandsuction,BraziliaN Journal of Chemical Engineerind.,vol.30, pp.187-1312,195, 2012.

[6] Elbashbeshy, E.M.A. and Dimian, M.F., Effect of Radiation on the Flow and Heat Transfer over a wedge with variable viscosity. Pplied Mathematics and Computation, vol. 132, pp. 445-454, 2002.

[7] Hossain, M.A., Alim and Rees, D.A.S, The Effect of Radiation on free convection from a Porous vertical plate. International Journal of Heat and Mass Transfer, vol.42, pp.181-191, 1999.

[8] Bataller, R.C., Radiation effects in the Blasius flow. Applied Mathematics and computation, vol.198, pp.333-338,2008.

[9] Cortell, R., A Numerical Tacking on flow with Thermal Radiation. Chinese physics letters, vol.25, pp.1340-1342, 2008.

[10] M. Gnaneswara Reddy, "Influence of thermal radiation, viscous dissipation and hall current on MHD Convection flow over a stretched vertical flat plate," Ain Shams Engineering Journal, vol.5, no. 1, 2014; pp. 169-175.

[11] K. Vajravelu and A. Hadjinicolaou, "Heat transfer in a viscous fluid over a stretching sheet With viscous dissipation and internal heat generation,' InternationalCommunications in Heatand Mass Transfer, vol. 20, no. 3, 1993; pp. 417-430.

[12] F. M. Hady, F. S. Ibrahim, S. M. Abdel-Gaied, and M. R. Eid, "Radiation effect on viscous flow of a nanofluid and heat transfer over a nonlinearly stretching sheet," NanoscaleResearchLetters, vol. 7, article 229, 2012.

[13] K. Vajravelu, K. V. Prasad, and C.-O.Ng, "Unsteady convective boundary layer flow of a viscous Fluid at a vertical surface with variable fluid properties," Nonlinear Analysis: Real WorldApplications, vol. 14, no. 1, 2013; pp. 455464.

[14] T. Poornima and N. Bhaskar Reddy, "Radiation effects on MHD free convective boundary layer flow of nanofluids over a nonlinear stretching sheet," Advances in Applied ScienceResearch, vol. 4, no. 2, 2013; pp. 190-202.

[15] K. Vendabai and G. Sarojamma, "Unsteady convective boundary layer flow of a nanofluid over a stretching surface in the presence of a magnetic field and heat generation," International Journal of Emerging Trends in Engineering and Development, vol.3, no. 4, 2014; pp. 214-230.

[16] J. Buongiorno, "Convective transport in nano fluids," Journal of Heat Transfer, vol. 128, no. 3,2006 ;pp. 240-250.2007.

[17] F. M. Hady, R. E. Mohamed, and M. A. Ahmed, "A nanofluid flow in a non-linear stretching surface saturated in a porous medium with yield stress effect," Applied Mathematics \& InformationSciences Letters, vol. 2, no. 2, 2014; pp. 43-51.

[18] M.S. Khan, I. Karim, L.E. Ali, and A. Ismail, "Unsteady MHD free convection boundary-layer flow of a nanofluid along a stretching sheet with thermal radiation and viscous dissipation effect," International Nano Letters, vol. 2, article 24, 2012.

[19] M.A. Hamad, I. Pop, and A.I. Ismail, "Magnetic field effects on free convection flow of a nanofluid past a vertical semi-infinite flat plate, " Nonlinear Analysis. Real World Applications, Vol. 12, no.3, pp. 1338-1346, 2011. 